University of Wollongong

Research Online

Faculty of Law, Humanities and the Arts Papers (Archive)

Faculty of Arts, Social Sciences \& Humanities

$1-1-2019$

Young people, online fandom and the perils of child pornography legislation in Australia

Mark J. McLelland

University of Wollongong, markmc@uow.edu.au

Follow this and additional works at: https://ro.uow.edu.au/lhapapers

Part of the Arts and Humanities Commons, and the Law Commons

Research Online is the open access institutional repository for the University of Wollongong. For further information contact the UOW Library: research-pubs@uow.edu.au 


\title{
Young people, online fandom and the perils of child pornography legislation in Australia
}

\author{
Abstract \\ In 1971 the editors of Oz magazine were prosecuted for obscenity in a London courtroom for their \\ infamous 'School Kids Issue', almost the entire contents of which had been created by a team of young \\ people. In today's Web 2.0 environment, similar kinds of content to that featured in the magazine is \\ created by young people and made ubiquitous on fan websites. In particular 'manips' (manipulated \\ images) of all kinds of pop culture heroes from boy band members to characters from Harry Potter are \\ inserted into pornographic contexts. Whereas in the 1970s it was obscenity legislation that was used to \\ restrict this form of cultural commentary, today child pornography legislation can be used to capture this \\ content. I argue that changes to child pornography laws across the western world in the last two decades \\ have resulted in the capture of even fictional images that are or may only 'appear to be' a person under the \\ age of 18, rendering some aspects of online youth culture problematic. The 'juridicial discourse' that \\ increasingly collapses a complex range of cultural representations into the category of child pornography \\ is a cause for concern for all academics working on online youth cultures and for the young people \\ involved \\ Disciplines \\ Arts and Humanities | Law

\section{Publication Details} \\ McLelland, M. (2019). Young people, online fandom and the perils of child pornography legislation in \\ Australia. International Journal of Cultural Studies, 22 (1), 102-118.
}




\title{
Young People, Online Fandom and the Perils of Child Pornography Legislation in
} Australia

\begin{abstract}
In 1971 the editors of $\mathrm{Oz}$ Magazine were prosecuted for obscenity in a London courtroom for their infamous "School Kids Issue," almost the entire contents of which had been created by a team of young people. In today's web 2.0 environment, similar kinds of content to that featured in the magazine is created by young people and made ubiquitous on fan websites. In particular "manips" (manipulated images) of all kinds of pop culture heroes from boy band members to characters from Harry Potter are inserted into pornographic contexts. Whereas in the 1970s it was obscenity legislation that was used to restrict this form of cultural commentary, today child pornography legislation can be used to capture this content. I argue that changes to child pornography laws across the western world in the last two decades have resulted in the capture of even fictional images that are or may only "appear to be" a person under the age of 18 , rendering some aspects of online youth culture problematic. The "juridicial discourse" that increasingly collapses a complex range of cultural representations into the category of child pornography is a cause for concern for all academics working on online youth cultures and for the young people involved.
\end{abstract}

Key words: Oz magazine, obscenity, child pornography, youth, fandom, manips

Mark McLelland, University of Wollongong, markmc@uow.edu.au

Funding: Research for this article was supported by Australian Research Council grant FT120100388 


\section{Young People, Online Fandom and the Perils of Child Pornography Legislation in}

Australia

\section{Mark McLelland}

\section{Background: the $O z$ School Kids Issue}

In June 1971 a landmark trial was launched in London under the Obscene Publications Act 1959 against the three editors of $\mathrm{Oz}$ magazine, an irreverent underground publication that had started its life in Sydney in 1963 and had moved its publication base to London at the end of that decade. The impetus for the trial was the May 1971, number 28 issue, better known as "School Kids Oz" since its contents had been brought together by an editorial team consisting of twenty or so young people between the ages of 14 and 18 under the supervision of the magazine's editors. Among the charges laid at the three adult editors was one of conspiracy, namely that they had conspired to "corrupt the morals of young children and other young persons" by producing an "obscene article." One example of the obscenity cited in the trial was the creation of Vivien Berger, a 15-year-old schoolboy. Berger had produced a montage of two different comic strips, one a pornographic comic created by American underground artist Robert Crumb, and the other, the much loved children's character Rupert the Bear. The manipulated comic strip, which appears on pages 14 and 15 of the publication, shows an inquisitive and sexually aroused Rupert violating an unconscious elderly woman. ${ }^{\mathrm{i}}$

During the trial when Berger was called as a witness he was asked what his motivation had been in creating the pastiche. His reply did little to support the "conspiracy to corrupt" charge. Berger argued that he created the comic in order to "shock your generation" (cited in Palmer 1971: 175). Palmer's account of the trial (based on transcripts of the proceedings) shows that what most disturbed the prosecution was not the violence or inherent misogyny of Crumb's original cartoon but the juxtaposition of these images with Rupert the Bear -- a nostalgic image of childhood innocence.

Anxieties about the juxtaposition of sexual imagery with images of childhood have only been enhanced in the decades following the trial and the legal mechanisms available to regulate this kind of material have been transformed in both nature and scope. In particular the broadening scope of material caught by child pornography laws to include purely fictional 
characters and scenarios means that the kind of montaged image created by Berger, and replicated today in digital environments by young people who produce similarly incongruent juxtapositions, is liable to be caught by such laws. In this paper, the implications of the expanded scope of child pornography legislation for common fan practices will be discussed, primarily from an Australian point of view (since this is the author's country of residence). However the gradual expansion of these laws is an international trend and I discuss literature pointing to the chill effects of parallel legislation elsewhere. I argue that the expansion of child pornography laws to capture fictitious characters and scenarios has rendered contentious areas of cultural expression involving childhood perilous for creators, audiences and researchers alike, made informed commentary on these activities impossible and has correspondingly made important aspects of fan culture unknowable.

\section{Changing constructions of childhood}

In some ways it is hard to compare contemporary understandings of childhood with those at work in the late 1960s and early 70s given that the latter was a period of rapid social change largely driven by youth culture. Getting a bunch of school kids together for the express purpose of launching an anti-establishment tirade certainly fit the mood of the times, and it was a constant refrain in the defence of the magazine's adult editors that it was not they who were responsible for that specific issue's contents but the school kids themselves who had chosen the material and executed the design. One need only look at the content of the issue itself to see multiple examples of the young contributors' attempts to expose adult hypocrisy, double-standards and abuse. A case in point is an illustration on page 10 accompanying a list of vignettes entitled "School atrocities" which mentions scenes of sexual impropriety, if not outright abuse. As the text, also contributed by Berger, notes "Like - the ageing master who used to walk around the juniors' showers 'cleaning his glasses' as he looked at the kids' balls saying sometimes 'I don't think I've seen you before'." The illustration shows a tartan-suited master vigorously masturbating as he touches a male pupil's backside - the pupil vomits in response. The next page has an illustration of three school masters excitedly drooling while caning each other's naked buttocks.

Given the testimonies currently before an Australian Royal Commission into child sexual abuse (Ceranic 2015) and the findings of the many cognate investigations launched around the western world in the last three decades, the kind of scenario described in Berger's 
vignette does not seem fantastic and indeed might even be thought commonplace. It is clear that the sexual abuse of children was taking place (and being covered up) in private and public schools, in the Scouts, in orphanages and care homes, at correctional facilities, in hospitals, in the entertainment world and in churches of various denominations. These abusers were not, on the whole, anonymous and adventitious paedophiles, but the very people who were supposed to be in charge of the education of the young: their teachers, guardians, doctors, entertainers, priests and parents. The scale of these abusive scenarios and the tendency of adults to look the other way, actively cover up the activities of their peers, or simply fail to recognise certain actions as abusive in the first place, helps make sense of the general tone of the $\mathrm{Oz}$, School Kids' issue, and requires us to take more seriously the attempts by these young people to expose as well as satirize the behaviours of a corrupt and hypocritical older generation.

We are now distant from a mentality that could propose that a magazine, especially an underground publication already mired in controversy, should turn itself over to a group of school children to do with as they wished without adult interference. There has been a welldocumented movement toward increased scrutiny of young people's reading matter and media use more generally, with calls for a whole range of materials to be taken off curricula or for young people's access to be limited (Jenkins 2011). The now commonplace notion of "age-appropriate" content would make it unlikely to give those between fourteen and eighteen free rein on a media project. As Beattie points out "the stratification of codes of representation across different age groups ... . is a key tool in the constitution of autonomy and the social construction of the image of the child" (2009: 17). It also functions as "a moralizing regulator to legitimate the marginalization of young people's opinions" (Johnson Ross 2013: 114). Would satirical art-work such as Berger's masturbating school master be given space in a commercial publication today?

The young people's involvement in the $O z$ School Kids' issue has some similarities with a contemporaneous development that took place in the UK city of Bath in the same year. At the time this historic city was also home to a large council estate on its fringes complete with high levels of youth unemployment and crime. One of the city's arts groups, the Natural Theatre Company, had applied to the Council for funding to create a youth adventure playground on some derelict land adjoining the estate. Although the Council denied the funds, an alliance with the University of Bath enabled the company to open the playground and host daily between 60 and 100 children from ages 9 to 14 over the summer holidays. The stated 
aims of the playground were to reduce vandalism, encourage racial integration and stimulate creative activity. Activities sponsored with this in mind included "the building of huts, walls, forts, tree houses, lighting fires and cooking, tree climbing, digging, camping, as well as playing team games, painting, dressing up, modelling, reading or just doing nothing" (Peterson 2011: 391). In line with the theatre group's ethos, these activities were aimed at "creating alternative worlds" and experimenting with "new modes of engaging with each other" (Peterson 2011: 392).

Although from contemporary perspectives the idea of up to 100 young people fourteen and under running round a building site erecting temporary structures, covering them in graffiti and burning them down seems unmanageable, it is the kinds of sexual transgression that were allowed in the playground that seem most striking. One instance included an imitation of the glamorous and sexy rock bands of the time which involved the children dressing up and parodying the highly sexualised antics of the adult performers. The idea for these dress ups and parodies came from the children themselves. Grant Peterson, author of an article retracing the history of the Bath playground, draws a direct parallel with the $O z$ editors, noting how both groups of adults were "willing to take risks by incorporating pre-adolescents into sexually tabooed activities" (2011: 395). He notes that this was an intelligible course of action at the time because legislation governing sexuality, including children's sexuality, was being fiercely contested - the $O z$ obscenity trial being a case in point. It was an acceptable idea, at least among more liberal sections of society, that young people had rights to selfexpression that included the critique of adult sexual mores and actions.

Forty years later, the ideas that young people might have their own understandings of "sexual subjectivity" and, rather than being passive recipients of adult moralizing, might seek out ways to "resist or contradict" adult perspectives (Johnson Ross 2013: 111) are still not given much credence, in official government policies, at least. As Johnson Ross points out in the UK, even as late as 2010, guidelines for the teaching of Sex and Relationship Education in schools work "to produce subjects engaged in self-regulation in line with the aims and morality of central government" and have little to say about how young people might "develop and enact their own sexual subjectivity" (2013: 111). There is little acknowledgement in government discourse, at least, that young people are agents in their own right who may have important things to say about adult society, its hypocrisy and mores. Sex education materials in particular reflect "the historic role of the state in conceptualizing 
young people as in need of moral training" (Johnson Ross 2013: 113) resulting in a "missing discourse of desire" (Harris 2005: 42).

In contemporary culture, due to enhanced awareness around issues of power and child sexabuse brought by second-wave feminism in the 1970s and 1980s, and the exposure of endemic abuse across a range of social institutions, there has been a formalisation of reporting mechanisms and an increased willingness to hear and respond to cases of abuse (Angelides 2004). These factors, alongside relentless media interest in stories of child-abuse and sexual predation, have resulted in childhood becoming "an enduring and privileged site of anxiety" whereby children "are regarded as by their nature vulnerable, in danger and in need of protection" (Ashenden 2002: 199-200). However, albeit stories of children as victims are more readily apparent in the media, there is an absence of what Karaian (2012: 59) refers to as "counter-narratives" where young people are shown to demonstrate sexual agency and knowingness. These "alternative ways of knowing and being" voiced by young people themselves are liable to be censored or subject to "implicit foreclosure" by dominant discourses that acknowledge children as victims of sexual activity but not as sexual agents in their own right (McLelland 2017a; Karaian 2012: 64; see also Harris 2005; Angelides 2004).

The general ethos concerning children has continued to shift toward a more risk-conscious assessment of their activities, especially where sexuality is concerned (Hacking 2003: 44). However children's own risk taking in the realm of sexual self-expression has not, in fact, decreased, it has simply developed new forms of expression, specifically online (Karaian 2012: 69). One aspect of this risk taking that has received academic and media interest is socalled "sexting," a term not used by young people themselves, but a description coined by the media for sexually explicit pictures and messages exchanged among teens (Karaian 2012: 64).

The activities I discuss below do not involve the swapping of "selfies" (that is, pictures of their own bodies) by young people but the exchange of sexualised images and stories about fictitious characters such as manga and anime figures as well as fictitious characters that are played by real actors, such as the young people in the Harry Potter universe. The creation and exchange of montaged versions of these characters that take elements from different screen shots and other images and blend them together in a new image, known as "manips" (that is photo manipulations), is a common fan practice. In some fan forums it is not uncommon for these images to include sexual scenarios. Although widespread, the practice has so far largely been overlooked by legal and cultural studies commentary on child 
pornography law. Yet, due to changes in the scope of this legislation across Australia, North America and Europe so that it now captures manipulated photographs of real persons as well as images of fictitious, non-existent persons, young people's fan activities have been rendered vulnerable to prosecution by these laws which also make the investigation of these fandoms by academics problematic and at times impossible (Galbraith 2017; Madill 2015; McLelland 2017a; 2017b; 2012).

\section{Parody, sexuality and child abuse}

Back in 1971, Vivien Berger, the creator of the Rupert the Bear montage that landed $O z$ magazine's adult editors on trial, was not himself prosecuted for his involvement. Instead he was presented to the court as an example of one of the children who had potentially been corrupted, although this victim role was not one that his smart and acerbic responses to the prosecution's questions supported. Indeed, even his mother, who was called as a witness for the defence, admitted that "what has done him harm is the fact that the whole thing has been blown up out of all proportion" (cited in Palmer 1971: 175). Yet, had Berger created such a visual today, in Australia and potentially elsewhere, he may have found himself in a rather different relation to the law - as both a producer and purveyor of a "child abuse image."

In the 1970s when child pornography laws began to be formulated, legislation targeted only photographic and other records of abuse against actual children. Since the roll out of the internet in the mid-1990s, however, the kind of material captured has been expanded to encompass some kinds of "virtual" (that is, fictitious, manufactured images) that under some codes, including in Australia, can include cartoon-like characters (McLelland 2017a; 2017b; 2012; April 2012; Coleman 2009: 198-205; Eiland 2008). This expansion constitutes a significant departure from the harm principle underlying previous legislation, Byrne Hessick noting that it "transforms child pornography law into a system for enforcing popular morality - specifically, popular disgust at the sexualisation of children" (2016: 73). One result has been that in the contemporary environment "in an effort to condemn all materials that might hold some special inciting effect upon alleged pedophiles, the judicial pedophilic gaze is extending to materials that are increasingly mundane" (Danay 2005: 156).

That even cartoon characters and other fictive "persons" can fall within the scope of Australian legislation was clarified in a 2008 decision pertaining to section s $91 \mathrm{H}(3)$ of the 
Crimes Act 1900 (operative in the Australian state of New South Wales) by Justice Adams in a case relating to manipulated images of the children in The Simpsons. Adams noted that "the mere fact that the figure depicted [Bart Simpson] departed from a realistic representation in some respects of a human being did not mean that such a figure was not a 'person'" (McEWEN v SIMMONS \& ANOR [2008] NSWSC 1292, para 41). In treating fictitious cartoon characters as "persons" under child pornography laws, Australian law is consistent with legislation across other commonwealth jurisdictions. These include the 2009 Coroners and Justice Act, 383 subsection (8) in the United Kingdom (Madill 2015; Johnson 2010) and the 2001 judicial decision in $R v$ Sharpe in Canada (Johnson 2006). In the United States, where First Amendment rights have complicated the expansion of these laws to an extent (Byrne Hessick 2016: 61-62; Coleman 2009), the 2003 PROTECT Act Section 1466A also criminalizes possession of "a visual depiction of any kind including . . . a cartoon" that depicts "a minor engaging in sexually explicit conduct" that is also "obscene" (April 2012: 250-53; see also Eiland 2008).

Justice Adam's ruling made plain that in the eyes of the law in Australia even imaginary characters can and do have a chronological age. With regard to the $\mathrm{Oz}$ case, in the fictional world of the comic, Rupert is clearly not of the age of majority and hence the juxtaposition of a young boy/bear in a "sexual scenario" is sufficient for the image to be scrutinised under current child abuse publications legislation. What is of concern about the use of Rupert the Bear is that the technique that Berger used to create the image, a kind of montage, where he substituted Rupert's head for that of a human character in a pornographic comic, is a common artistic practice engaged in by young people across a variety of online fan forums. The technique is referred to as photo-manipulation or "manip" for short and involves the juxtaposition of elements from one or several photos, videos or screen captures to create a new scenario (see Brennan 2013). These manipulated images can be put to various uses including the trolling and harassment of other internet users by tricking them into viewing pictures with offensive violent, racist or sexist content (Jones 2010: 128-29). However, consonant with my previous work on fandoms (McLelland 2012; 2017a; 2017b) in this paper I am concerned with their circulation among fans, particularly largely female "slash" fandoms that involve content taken from both Japanese and western pop cultures. Many manips are playful and imaginative re-creations that superimpose images of the manipulator her- or him-self into a scene from a TV series, anime or movie, or with celebrities. Other manips may create a scene consisting of unrelated celebrities (say, to imply a relationship 
between popular teen idols) or take fictional characters from their own screen world (say the brothers from TV series Supernatural) and transpose them into a different fictive world. ${ }^{\text {ii }}$

Although these manips can stand alone, they are often accompanied by short fan fiction "ficlets" contextualising the relationships depicted which requires the creators to produce a back-story and otherwise render the relationship intelligible in terms of the relations implied or established in the source text itself. It is also a common practice to invite comments from viewers on manips, fan fiction and other fan creations, thus increasing the reflexivity and discursivity around these fan practices. This feedback process requires what Brennan (2013) terms a "semiotic significance of selection" - in order for a manip to "work" and receive appreciative feedback from viewers, the creator has to display a range of literacies concerning the source text, the characters and the dynamics of the acts portrayed. Hence the kinds of images I am referring to in this paper are quite different from those created with the intent to abuse, harass and ultimately silence other internet users, or the kind of "shock images" that, because of their offensive content, "are relegated to less public locales" on the internet (Jones 2010: 126). Rather, sexualised fan manips can occur across a wide range of fan spaces including highly visible platforms for the dissemination of fan works, as discussed later in the article.

Apart from legal issues with the copyright of the original images, the law in Australia and elsewhere renders this popular mode of entertainment and social commentary problematic. In Australia this is largely to do with the "Refused Classification" or RC rating which according to the hierarchy of impact outlined in the Attorney-General Department's "Guidelines for the Classification of Films" contains scenes whose impact is judged "very high" (2012: 3). The use of the category referred to as RC in Australia differs in some respects from how ratings are administered in other countries. The RC rating not only includes material that would be illegal under the criminal code, such as child pornography or instruction in crime, but a wide range of elements that are considered too impactful and thus must be kept away from the viewing public. Regarding officially produced and distributed media content, the most visible arena in which the category of RC has been applied is video games. Australia does not "ban" games that are considered to have too high an impact on players but refuses to classify them meaning that they cannot be imported, sold or otherwise made available to the public essentially limiting their impact through controlling their distribution. However as Beattie points out, this is in effect a kind of censorship, since offending material, in order to find a 
market, must be made "compliant" with the classification system, and if it fails to comply, the material is "exiled to the margins" (2009: 3). Of course one problem with this system is that the internet provides multiple platforms for media distribution which evade official distribution channels, effectively meaning that there are no longer any meaningful margins. Certain kinds of material may well be kept out of the retail environment - but many people, including many youngsters, do not shop for content anyway - but search for it and share it across social media. Indeed the seamless way in which a google search can take a user from officially sanctioned sites, say regarding the Harry Potter franchise, to fan sites containing material that would be rated $\mathrm{RC}$ is difficult to regulate using existing mechanisms (McLelland 2017a; 2012: 471). For instance, Tumblr, YouTube, Facebook, Reddit and other mainstream sites feature multiple examples from the Harry Potter books where the word "wand" has been replaced by "penis" (Hodgson 2015). What commentators have failed to notice is that this substitution can transform the source text into a potential child-abuse publication in Australia and elsewhere.

Another problem with the RC category is that it is not only applicable to officially distributed media content, but can be applied to any Web content that contains this "high impact" material. I am not the first researcher to point out how problematic the $\mathrm{RC}$ rating is to fan communities whose user generated creations play with these edgy scenarios. As early as 1999, for instance, Danny Yee investigated the application of the Australian ratings system to a USbased erotic fiction website, noting in his analysis that the site contained "links to content that may be illegal in some states in Australia" (Yee, 1999).

Since Australia has no ratings system that applies specifically to different types of internetbased content, it instead uses the same guidelines that apply to film and video for all internet content. The material - textual and otherwise -- on fan sites would thus be rated according to how a film would be classified under the "Classification (Publications, Films and Computer Games) Act 1995." Among the Attorney-General's Department's "Guidelines for the Classification of Films" we find the following definitions of material rated RC:

- Detailed instruction or promotion in matters of crime or violence.

- Promotion or provision of instruction in paedophile activity.

- Descriptions or depictions of child sexual abuse or any other exploitative or offensive descriptions or depictions involving a person who is, or appears to be, a child under 18 years. 
- Gratuitous, exploitive or offensive depictions of: (i) activity accompanied by fetishes or practices which are offensive or abhorrent; (ii) incest fantasies or other fantasies which are offensive or abhorrent.

The prohibition of "incest" rules out one of the internet's longest running manip communities - "Wincest" or the slashing of the two Winchester brothers from Supernatural (Brennan 2014). Also prohibited are "fetishes", as well as fantasies that are "offensive or abhorrent" including sexualised violence that includes even consensual depictions "which purposefully demean anyone." All of these themes can crop up in manips as well as "darkfic" that seek to parody real world events and celebrities as well as fictional events and characters and to push at the boundaries of acceptable representation (see Brennan 2014; 2013; Jones 2010; and Hansen 2010 for examples). Indeed it is the deliberate creation of a particularly "offensive" juxtaposition - as we saw in the Rupert the Bear example - that makes this activity fun and exciting.

This kind of user generated material, building upon antecedents in the pre-internet "slash" fandoms examined by Jenkins in his ground-breaking Textual Poachers: Television Fans and Participatory Cultures (1992), has been a prominent feature of online communities since the early UseNet groups at the beginning of the 1990s. Sexualised fan materials are shared endlessly across social networking platforms, including LiveJournal, DeviantArt, ${ }^{\mathrm{ii}}$ Instagram, Tumblr and Twitter, where variants on a theme - for instance, the manipulation of characters from the Twilight or Harry Potter series - are shared, enjoyed and commented on by fans. As with the Rupert the Bear collage that featured in the $O z$ trial, it is often the desire to shock or offend that is played with in the production and dissemination of these images and fictions as can be seen in the multiple "reaction vids" posted on YouTube by young fans seeking to shock themselves, classmates, siblings or parents by searching for and displaying highly sexualised fan art, fiction and videos (see also Jones 2010: 135).

One Australian, Paul Yore, has already been subject to a court case for engaging in the kind of collaging activity typical of fan art, albeit in an offline setting (Faulkner 2014; ABC 2014). The facts that Yore was already an established artist, that the work was exhibited in a Melbourne gallery, and that the exhibition it was staged in had been given a rating of $\mathrm{R}$ (Restricted 18+) by the Classification Board, did not stop the prosecution going forward after an adventitious complaint by a member of the public that Yore's installation contained scenes of "child pornography." The complaint centred around several panels in a large installation 
work entitled "Everything is Fucked" that included a collage in which heads from children's advertisements, including several cut outs of a youthful Justin Bieber, had been included alongside sex toys and images from adult pornography. After a year of investigation and court hearings, the charges were eventually dismissed by the magistrate, but the dismissal hinged on the fact that the exhibition as a whole had already been deemed suitable for an adult public (that is, given its $\mathrm{R}$ rating) and the police were not able to demonstrate why this rating should be overturned.

My own knowledge of the online communities that create and trade in these kinds of problematic images and texts comes from decades' long engagement with scholars in Japan and the United States where robust constitutional defence of freedom of expression have placed limits on the ability of legislation to prohibit works of the imagination and thus afforded greater protection to academics working in the field of contentious imagery (see for instance the discussion in McLelland 2017b). Andrea Wood, for example, looking at "Boys Love" computer games based on manga and anime series "aimed at adolescent girls" argues that they offer important opportunities for "ludic (playful) pleasure" beyond "normative sexual ideologies" (2011: 355). For Wood it is the all-male cast of these games that is particularly attractive for girls since this allows them to bring male authority figures under their "sexual control" (2011: 363). Tosenberger notes, in regard to Harry Potter, that "Potter fandom is an arena in which fans of all ages, genders, and sexual orientations can tell stories to satisfy their own desires." She argues that "this freedom is especially valuable for younger fans, whose self-expressions are heavily monitored in institutional settings." She goes on to stress the positive benefits for young fans who "are able to tell narratives of sexuality in a space not directly controlled by adults, and do not have to shape their stories to adult sensibilities and comfort levels" (2008: 202). The emphasis on lack of adult surveillance is significant given that the sex depicted in these fan-authored creations certainly moves into a realm likely to be judged "offensive" for those outside the fandom, especially given the age of the characters.

I do not want to give the impression that these online spaces, often described as safe havens for the exploration of gender and sexuality, are without their own protocols or limits.

Different fan communities maintain different sensibilities about who constitutes a valid fan as well as about acceptable content and behaviour, as popular blogger in the "Johnny's" (a genre of Japanese boy band) fandom Marcus Herzig found out when he outed himself as a middleaged gay man in a fandom predominantly comprised of teen girls (Herzig 2012). What this 
suggests is that "offensiveness" is not necessarily a quality of a given representation - it can also depend on the perceived identity of its creator. Joseph Brennan (2014), one of few academics to have highlighted the politics of manip art in fan communities, has described how the self-proclaimed offline identities of some fan artists as well as certain pairings, acts and depictions can prove highly divisive and controversial even in fandoms that pride themselves on their transgressive attitudes (one of his main examples being the Supernatural fandom that deals in "Wincest"). He notes how certain "dark genres" within fandom skirt "parameters of taste and acceptability" (2013: 3). Hence, different people can be triggered by quite different scenarios, accepting some with equanimity while finding others unsettling, revolting or just plain “wrong." As Brennan points out "pearl-clutching nonnies" can be found even in fan spaces that delight in contravening social conventions (2014: 7).

Much of the literature does however suggest that the kind of fan production involving the sexualised manipulation of imaginary characters is weighted toward female participants and is youth-oriented. The literature on the whole is supportive, offering third-wave feministinspired readings, and stressing girls' and young women's sexual agency in the production and dissemination of this material. In relation to online sexual expression by those considered "under age," Lunceford acknowledges the role the media plays in the sexualisation of children but also points out how "children and adolescents are no longer merely consumers of this sexual ideology, but also creators of digital content that performs this ideology" (2011: 99). In some ways this is no different from the pantomime of adult sexual mores that also took place in an "alternative world" apparent in the Bath playground performance of glam rock discussed earlier in the paper. What has changed is the extent to which young people have gained agency in a digital environment not only for sexual self-expression but also for the critique of celebrity, media hype and the still stereotypical sex and gender system that is part of official education. Unlike the situation pertaining in the 1970s, however, much of this self-expression can now be captured by child pornography legislation on the premise that it may well offend a "reasonable [adult] person." Quite what the young people themselves engaged in these online communities might think about this material is hard to gauge in an Australian context, for the reasons outlined below.

\section{Implications of child pornography legislation for research on fan communities}


One problem for a researcher trying to investigate and comment upon the kinds of potentially infringing material generated and shared within these online fan communities as well as the kinds of persons and interactions that can be found there, is the impossibility of knowing two things in advance. Firstly, the exact content of a text or image prior to clicking on a link and secondly whether or not the material clicked on and thus now "possessed" by the viewer infringes the legislation or not. This is because most legislation is thin on detail about what comprises an obscene depiction or act, relying instead on the community standard test which invokes the imagined response of a "reasonable person" to the material in question. Much criticism has been levied at the limitations of this approach since it makes it difficult to predict in advance what kinds of material will contravene local sensibilities. As Braman points out, what is considered reasonable can be highly variable depending on who is asked, with people making designations "consistent with their worldviews" (2010: 1474). The "worldview" of a judge or jury is liable to be very different from that of the communities of fans in which these images circulate. As Madill has argued, the expansive nature of current child pornography laws that now capture even imaginary images "alerts hegemonically empowered or hegemonically representational groups to a paedophile reading, and disavows other possible readings as irrelevant if these groups can find that reading" (2015: 277; emphasis in the original). This has resulted in a situation where, as Johnson points out, "images widely available on the internet and often passed between friends, as 'a bit of a laugh' are now capable of giving those individuals a criminal record for possession of child pornography" (2010: 15).

This juridical reading of playfully provocative images as "child pornography" results in a "circumscribed field" of intelligibility (Kairan 2012: 64) that prevents anyone from discussing the material and its potential effects further. For instance, in the Yore trial mentioned earlier, potentially offending portions of Yore's installation were removed by police with a Stanley knife - destroying the integrity of the art work. As Faulkner comments, Yore's works "invite the viewer to reflect on contemporary culture's cooption of childhood in the name of consumption. They clearly do not invite the reader to enjoy the image sexually" (2014: 13; emphasis in the original) and yet the police intervention emphasised a sexual reading of the images by excising and drawing attention to only those specific portions.

An alternative approach to appraising deliberately non-realist and yet provocative images is suggested by Anne Allison who, in relation to pornographic manga asks, "how a sexual practice or text may work for someone it gives pleasure to rather than merely against 
someone it ideologically oppresses" (2000: 55; italics in the original). The banning of an image of which a potential paedophile reading can be made makes it hard to deal with material that was created with other intentions. This may include the intention to offend which was the case with many items included in the $O z$ school kids' issue where offending adults was a calculated strategy on the part of the young people involved. Likewise it closes down space for the legitimate sexual self-expression of young people for whom young or young-looking characters may provide age-appropriate fantasy material (Madill 2015: 285). Indeed work on adolescent psychology confirms that "sexual fantasy plays an increasingly important role in sexual expression" from puberty onward (Malin and Saleh 2014: 15) and that online spaces can be important venues for "intimacy practices" precisely because they are "outside the purview of [their] parents or other authority figures" (Pascoe 2009: 120; see also Harris 2005).

Current child pornography legislation thus requires the researcher to be overly cautious in investigating the kind of fan activities outlined above and deters immersion in the subcultures under investigation, making any kind of online ethnography impossible. It also complicates the ethics clearance procedure, inhibiting the researcher from interviewing and seeking firsthand insights and explanations from participants in these subcultures that might shed light on the complex ways in which meanings are assigned by participants themselves. This relates to question 15 on my university's Human Research Ethics application form which asks "Is information about criminal activity likely to be revealed during the study?" Only two possible answers are provided in the boxes underneath: Yes or No. Yet the reality of investigating this topic is that the answer to the question is not decidable in advance. It really depends on what a "reasonable person" may find offensive. We have several test cases, including the McEwan and Yore cases mentioned above, indicating that manipulated pictures of child-like cartoon characters and the mixing of adult and child images in a manip-like collage, when involving sexual acts or a sexual context, can be prosecuted. However, we do not have any test cases so far for online manips involving Harry and Draco in sexual congress - despite the fact that a simple google image search for "Harry Potter manips" would produce multiple examples of this and other pairings of characters from that imaginary universe in scenarios that may, or may not, offend a reasonable person. Such a google search produces images that link to popular platforms for fan art and text whose main users are young people, especially girls. It is not clear how such a case would play out in court if the defendant charged were a 13-year- 
old girl and the child-abuse "ring" she were part of consisted of her school chums on a mainstream social networking site.

This murky legislative area was further complicated in Australia in 2010 by the addition of a new offence under the Sexual Offences against Children Bill that made it a criminal act to "make available" objectionable content. The wording used is extremely broad, defining this as, "describing how to obtain access, or describing methods that are likely to facilitate access, to material (for example: by setting out the name of a website, an IP address, a URL, a password, or the name of a newsgroup)" (Crimes Legislation Amendment [Sexual Offences against Children Bill] 2010: 60; my italics). It is therefore unclear whether my discussing the prevalence of this kind of fan content on sites such as LiveJournal, Tumblr, DeviantArt or Instagram could be described as facilitating access (this university's Legal Office was unsure and consequently requested the removal of such references in a public lecture I gave on this topic some years ago). Certainly, reproducing such content in an article would be unwise essentially making it impossible for the images and texts in question to be viewed and debated in an academic context in Australia. This whole area of inquiry into fan activity involving sexualised images of young-looking characters in popular culture is basically off limits for legal and ethical reasons, at least to researchers based in Australia.

\section{Offensiveness and online play}

In conclusion I would like to offer a different paradigm for understanding the kinds of contentious practices I have been describing in this paper, one that does not assume that dire consequences follow on from the manipulation of young-looking fantasy characters in sexual scenarios, or accept that the offended feelings of (some) reasonable persons is a good reason to invoke the law to restrict (some other) people's freedom of expression.

In their book Transcending Taboos Young and Whitty (2012) point out how cyberspace has created "the possibility for new interactive spaces, and the construction of new social realities and new forms of embodiment" (2012: 22). They go on to inquire what, if any, relationship should offline moral values have in virtual worlds, asking "could a social space exist that is devoid of offline taboos, where such traditional taboo-based morality has no foothold, or must deep disgust constrain even our most virtual interactions because we import these taboos into whichever space we enter?" (2012: 22). They note how in an offline context, even 
potentially harmless acts such as consensual sibling incest or necrophilia (in which the deceased had willed their body to be used for sexual purposes) still results in "moral dumfounding," a deep sense of moral disgust despite any evident harm to the consenting participants. They question whether the same sense of moral dumbfounding also accompanies the virtual performance of such acts in cyberspace (either textually or via avatars). They note that many people would still feel a strong moral aversion to these acts but ask "would we (in virtual space) be warranted to do so?" (2012: 23).

In a virtual, fantasy scenario, it is unclear if the performance of certain actions that would be illegal and/or the source of moral dumbfounding if they occurred in actual life, cause any kind of harm to the participants who share these fantasies in virtual social spaces. It is not even clear if these behaviours are uniformly regarded as problematic or immoral by participants. As they note "the problem we presently face is that little is known about whether behaviours considered to be illegal offline, relationship transgressions or even deeply immoral, are viewed in the same way in a variety of other spaces online" (2012: 23). Indeed, some virtual spaces such as Second Life are set up to facilitate role-playing games that enable participants to act out fantasies that are disassociated from their identities in offline life (Coleman 2009). These might include online sexual affairs or playing with avatars that express different gender, age and sexual identities than their offline owners. Different online games and spaces will themselves have different rules concerning permissible actions and different players within these spaces will feel differently about different acts. To what extent should offline morality guide performances in these online fantasy spaces? As Sahlfeld points out "Criminal content and action are common features of games ... Games allow and even incite users to do things and express themselves in a way that is strictly prohibited and would be severely punished if done in the real world" (2010: 206).

Despite the complexities involved in understanding the online spaces noted above, the representation of children, including characters that may appear to be children, in such contexts is one area where public opinion is strongly oriented toward protectionism. There is something about the role that the imaginary of "the child" plays in contemporary societies that predisposes the majority of commentators toward strong emotional responses - even in cases (such as the fictional characters discussed above) where no actual child is harmed. This makes academic inquiry into these issues fraught. As April points out "the tendency to believe that these types of images have no conceivable social value" makes questioning the legislation difficult and their conflation with child pornography "makes the topic so 
distasteful that attorneys and legal scholars would rather have nothing to do with it" (2012: 264).

As Lowenkron (2013), Kairan (2012) and Faulkner (2014), among others, have argued, there is something about how rhetorical invocations of the "innocence" and "vulnerability" of children have been institutionalized via legislation and media discourse in contemporary societies that make it extraordinarily difficult to present perspectives that critique this position without inviting moral condemnation. Indeed, raising concerns about the expanding scope of child pornography laws can result in the "framing [of] those who dare to oppose the strictest regulation of child pornography as hopelessly misguided libertarians, pedophiles, or both" (Danay 2005: 153) as is increasingly attested to by researchers in the field of contentious images (Galbraith 2017; Stapleton 2013; Kincaid 2004). Yet, as Cather notes, we need to "flip [the] presumption of harm on its head to consider also the benefits of such work" and affirm as academics the "deep need to see, to feel and to know things both inside and outside our comfort zones" (2017: 87-88). This may include investigating and reporting on imagery that some sections of the community may feel vehemently opposed to; as Jones suggests, we "need to look for ways of accounting for the presence and appeal of such imagery, rather than simply trying to obscure, deny, or, legislate against it" (2010: 136).

So, to sum up, the manner in which Australian legislation captures the playful manipulation of imaginary worlds, assigns personhood to cartoon characters and otherwise mixes up fantasy materials with the abuse of actual children makes discussing these online practices a fraught enterprise, even in an academic context. The legislation also muddies the waters by conflating the abuse of real children (as recorded in actual photographic evidence of child abuse) with the representation of "abuse" carried out on and by fictional characters who may "appear to be" children, the creators of which may well themselves be under 18. The breadth of material now captured encourages a "paedophile reading" even in circumstances (such as the Paul Yore case or the various fandoms under consideration) where this reading is contrary to that intended by the producers or adopted by the target audiences.

There is little acknowledgement in juridical discourse that young people themselves may be sexual agents, and may actively choose to critique, comment on and play with images of sexuality found in popular culture, despite academic work pointing to the contrary (Mahill 2015; McLelland 2017a, 2012; Karaian 2012; Harris 2005; Angelides 2004). The potential 
over-reach of child pornography legislation discussed above is a pertinent example of Lunceford's point that "the law as it currently stands exposes the fissures between what is considered normal adolescent sexuality and the lived experience of adolescents" (2011: 111). Although there have so far been no cases in Australia where young people have been prosecuted for exercising their imaginations in terms of sexual fiction, that possibility exists and the legislation as it is currently framed inhibits research into this significant area of popular culture, an area only likely to expand in the future.

If fan manipulations of under-age fantasy characters are really so serious as to pose a threat to actual children, then, given the scale of the offending, surely this is an area demanding intense scrutiny and research? Unfortunately the framing of the legislation and the general aversion to seeming soft on child protection means that those inside the academy with the appropriate skills for understanding these communities, their practices and the meanings of the images created are barred from investigating them in a systematic manner. This dense crossover of legislation, university ethics procedures, media commentary and community expectations has resulted in making a common form of online sexual self-expression undertaken by many young people unknowable. It is difficult to see how this knowledge vacuum can serve the needs of child protection or how its perpetuation can contribute to the urgent need to respond to real acts of child abuse both in the past and present.

\section{References}

ABC (2014) "Pornography Charges against Paul Yore Dismissed," ABC Arts Online. Available at: http://www.abc.net.au/arts/blog/arts-desk/Artist-Paul-Yore-acquitted-ofpornography-charges-141001/default.htm

Allison, Anne (2000) Permitted and Prohibited Desires: Mothers, Comics and Censorship in Japan, Oakland: University of California Press

April, Keisha (2012) “Cartoons Aren't Real People too: Does the Regulation of Virtual Child Pornography Violate the First Amendment and Criminalize Subversive Thought?" Cardozo Journal of Law \& Gender, 19(241): 241-271.

Angelides, Stephen 2004. "Feminism, child sexual abuse and the erasure of child sexuality." GLQ, 10(2): 141-77. 
Ashenden, Samantha (2002) "Policing Perversion: The Contemporary Governance of Paedophilia," Cultural Values 6(1\&2): 197-222.

Attorney-General's Department (2012) Guidelines for the Classification of Films. Haymarket, NSW: Attorney-General's Department Classification Branch.

Beattie, Scott (2009) Community, Space and Online Censorship. Farnham: Ashgate.

Braman, Donald (2010) "Cultural Cognition and the Reasonable Person," Lewis \& Clark Law Review, 14: 1455-1480.

Brennan, Joseph (2014) "Fandom is full of pearl-clutching old ladies: Nonnies in the online slash closet." International Journal of Cultural Studies, 17(4): 363-80.

Brennan, Joseph (2013) "Slash manips: Remixing popular media with gay pornography." M/C Journal 16(4), available at: http://journal.mediaculture.org.au/index.php/mcjournal/article/viewArticle/677 (accessed 24 August 2015).

Byrne Hessick, Carissa (2016) "Setting Definitional Limits for the Child Pornography Exception," in: Carissa Byrne Hessick (ed.) Refining Child Pornography Law, Ann Arbor: University of Michigan Press, pp. 57-77.

Cather, Kirsten (2017) "Must We Burn Eromanga? Trying Obscenity in the Courtroom and the Classroom," in Mark McLelland (ed.), The End of Cool Japan: Ethical, Legal, and Cultural Challenges to Japanese Popular Culture. London: Routledge, pp. 70-93.

Ceranic, Irena (2015) "Hundreds of child sexual abuse complaints referred to police: royal commission chair" ABC News. Available online:

http://www.abc.net.au/news/2015-07-15/child-abuse-royal-commission-chairspeaks/6621742

Coleman, Sabryne (2009) "You Only Live Twice: How the First Amendment Impacts Child Pornography in Second Life," Loyola of Los Angeles Entertainment Law Review, 29(193): 193-232.

Danay, Robert (2005) “The Danger of Fighting Monsters: Addressing the Hidden Harms of Child Pornography," Review of Constitutional Studies 11(1): 151-91.

Eiland, Murray Lee (2009) "From Cartoon Art to Child Pornography," International Journal of Comic Art 11(2): 396-409. 
Faulkner, Joanne (2014) “Censorship, Nudity and Childhood Innocence: From Henson to Yore," Dancehouse Diary, Issue 6: 12-13.

Galbraith, Patrick (2017) ““The Lolicon guy”: Some observations on researching unpopular topics in Japan," in Mark McLelland (ed.), The End of Cool Japan: Ethical, Legal, and Cultural Challenges to Japanese Popular Culture. London: Routledge, pp. 109-33.

Hacking, Ian (2003) "Risk and Dirt" in Richard Ericson, and Aaron Doyle, eds, Risk and Morality. Toronto: University of Toronto Press.

Hansen, Brita. 2010. "The darker side of slash fiction on the internet." In A Mousoutzanis and D Riha (eds), New Media and the Politics of Online Communities, Oxford: InterDisciplinary Press.

Harris, Anita (2005) Discourses of desire as governmentality: Young women, sexuality and the significance of safe spaces. Feminism and Psychology 15(1): 39-43.

Herzig, Marcus. 2012. Memoirs of a Johnny's Fanboy. Create Space Independent Publishing Platform.

Hodgson, Claire (2015) "Replacing the Term 'Wand' with 'Penis' in Harry Potter Never Gets Old." Cosmopolitan. Available online:

http://www.cosmopolitan.com/uk/entertainment/news/a39198/harry-potter-wand-penisreplacing/

Jenkins, Christine (2011) “Censorship: Book Challenges, Challenging Books and Young Readers," in: Shelby Wolf, Karen Coats, Patricia Enciso and Christine Jenkins (eds) Handbook of Research on Children's and Young Adults' Literature, New York: Routledge, pp. 443-54.

Jenkins, Henry (1992) Textual Poachers: Television Fans and Participatory Cultures, Lonond: Routledge

Johnson, Maureen (2010) "Freedom of Expression in Cyberspace and the Coroner's and Justice Act 2009," in: 3rd International Seminar on Information Law. Available at: http://researchprofiles.herts.ac.uk/portal/en/publications/freedom-of-expression-in19 cyberspace-and-the-coroners-and-justice-act-2009(f62ec992-d9c8-4a26-8e60ccc5b28430d8).html Accessed January 27, 2016. 
Johnson, Travis (2006) "Child Pornography in Canada and the United States: the Myth of Right Answers," Dalhousie Law Journal, 375: 376-411.

Johnson Ross, Freya (2013) “Are We Nearly There Yet? Struggling to Understand Young People as Sexual Subjects," Graduate Journal of Social Sciences 10(1): 104-123.

Jones, Steven (2010) "Horrorporn/Pornhorror: The Problematic Communities and Contexts of Online Shock Imagery," in: Feona Attwood, ed., Porn.com: Making Sense of Online Pornography, New York: Peter Lang, pp. 123-37.

Kincaid, James (2004) "Producing Erotic Children" in Steven Bruhm and Natasha Hurley (eds.), Curiouser: On the Queerness of Children. Minneapolis: University of Minnesota Press, pp. 3-16.

Lowenkron, Laura. 2013. “All against Pedophilia:” Ethnographic notes about a contemporary moral crusade. Vibrant: Virtual Brazilian Ethnography 10(2). Available online: http://www.scielo.br/scielo.php?script=sci_arttext\&pid=S1809-43412013000200002 Madill, Anna (2015) “Boys’ Love Manga for Girls: Paedophilic, Satirical, Queer Readings and English Law," in Emma Renold, Jessica Ringrose and Danielle Egan, eds, Children Sexuality and Sexualization, New York: Palgrave Macmillan, pp. 273-88.

Malin, Martin and Fabian Saleh (2014) "Sexual Development and Behavior in Children and Adolescents," in Fabian Saleh, Albert Grudzinskas and Abigail judge (eds) Adolescent Sexual Behavior in the Digital Age, Oxford: Oxford University Press, pp. 43-61.

McLelland, Mark. (2017a) “'Not in front of the parents!'” Young people, sexual literacies and intimate citizenship in the internet age." Sexualities, 20(1-2): 234-54.

Mark McLelland (ed.) (2017b) The End of Cool Japan: Ethical, Legal, and Cultural Challenges to Japanese Popular Culture. London: Routledge.

McLelland, Mark. 2012. “Australia's 'child-abuse material' legislation, internet regulation and the juridification of the imagination." International Journal of Cultural Studies, 15(5): 467-83.

Palmer, Tony. 1971. The Trials of Oz. Manchester: Blond and Briggs. 
Pascoe C.J. "Intimacy" in Mizuko Ito (ed.), Hanging Out, Messing Around and Geeking Out: Kids Living and Learning with New Media, Cambridge MIT Press, pp. 117-48.

Peterson, Grant Tyler. 2011. "Playgrounds which would never happen now, because they'd be far too dangerous: Risk, childhood development and radical sites of theatre practice." Research in Drama Education: The Journal of Applied Theatre and Performance, 16(3): 387-402.

Sahlfeld, Miriam. 2010. "The protection of minors and its effect on cultural diversity: An example of content regulation in digital game environments." In Graber C B and BurriNenova M (eds) Governance of Digital Game Environments and Cultural Diversity. Cheltenham: Edward Elgar, pp. 202-36.

Stapleton, Adam (2013) "Border Patrol: Trevor Brown, Aesthetics, and the Protection of Fictitious Children" in Feona Attwood, Vincent Campbell, I.Q. Hunter and Sharon Lockyer (eds.), Controversial Images: Media Representations on the Edge. Hampshire and New York: Palgrave Macmillan, pp. 115-130.

Tosenberger, Catherine. 2008. "Homosexuality at the online Hogwarts: Harry Potter slash fanfiction, Children's Literature 36:185-207.

Wood, Andrea. 2011. “Choose your own queer erotic adventure: Young adults, boys' love computer games and the sexual politics of visual play." In Abate MA and Kidd K (eds) Over the Rainbow: Queer Children's and Young Adult Literature. Ann Arbor: University of Michigan Press, pp. 354-78.

Yee, Danny. 1999. "Classification and Collateral Damage”. Online: http://danny.oz.au/freedom/99/classification.html.

Young, Gary and Monica Whitty. 2012. Transcending Taboos: A Moral and Psychological Examination of Cyberspace. Hove: Routledge.

\section{Notes}

\footnotetext{
'A scan of the full School Kids issue, including Berger's montage, is available on the University of Wollongong's online repository at : http://ro.uow.edu.au/ozlondon/28/
} 
ii See for example The Supernatural brothers Sam and Dean "manipped" into an iconic poster for Ang Lee's movie Brokeback Mountain at: http://morganbriarwood.net/fanart/v/spn/SPN-BBM600.jpg.html iii LiveJournal and DeviantArt have content restrictions including a no nudity policy regarding images. However this is circumvented by fans who simply provide a censored version of the image on their page and provide a link to the uncensored image hosted on image sharing sites such as imgur or Tumblr. 